\title{
Renal Cell Carcinoma with venous neoplastic thrombosis: A ten years review
}

\author{
Giacomo Maria Pirola, Giovanni Saredi, Giuseppe Damiano, Alberto Mario Marconi \\ Urology Unit, Ospedale di Circolo e Fondazione Macchi, Varese, Italy.
}

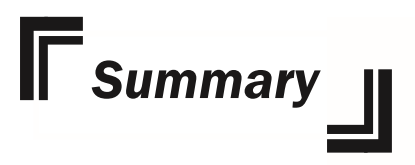

Purpose: To review the 10-year experience of our urological unit in the surgical management of renal cell carcinoma (RCC) with neoplastic tumor thrombosis focusing on postoperative survival.

Materials and Methods: We underwent a retrospective analysis of the patients treated for this pathology during the last decade 2002-2012, stratifying them by tumor thrombus level and histological subtype. Kaplan-Meyer curves were used to assess survival. Results: Overall, 67 patients underwent surgery for RCC with neoplastic tumoral thrombosis in the period under review. 60 were clear cell RCC, 4 were urothelial papillary tumors of the renal pelvis and 3 were rare histotypes, as a nefroblastoma, a spinocellular tumor of the renal pelvis and an unclassifiable renal carcinoma. Thrombus level was I in 40 cases, II in 17, III in 2 and IV in 8 patients. We report the main postoperative complications and our survival data, with mean follow up of 36 months. Tumor stage is the most important variable in predicting survival. Patients with NOMO disease had $70 \%$ survival at 36 months, instead of $20 \%$ for those with primitive metastatic tumor.

Conclusion: Our survival results fit with the main reports in literature and our surgical management was completely in keeping with international guidelines. We did not observe relevany post-operative complications, except of hemorrhagic ones that occurred in 6 patients (9\% of total) and were always successfully managed. Eighteen patients (26.87\% of total) underwent caval filter positioning, without evidence of complications during its positioning or removal. Life expectancy was particularly low for the cases of RCC without clear cell histotype (7 cases in our series, $10.4 \%$ of total) that always was less than one year from surgery.

KEY WORDS: Renal cell carcinoma; Neoplastic tumor thrombus; Neves e Zincke criteria; Surgery; Survival curves.

\section{INTRODUCTION}

Renal cell carcinoma (RCC) has a very well known angiotropism, with up to $10 \%$ of tumors presenting neoplastic tumoral thrombosis (1). Surgical treatment of this pathology is one of the most challenging procedures in Urology, requiring optimal surgical skills and collaboration of many other specialists, like radiologist, heart-surgeon, general surgeon and oncologist (2-4). Nowadays, most of urologic treatments can be offered in mini-invasive way (5), but the challenges of this procedure are still to be faced by open surgery (6). The aim of this paper is to review the 10 year experience of our institution in the sur- gical management of renal cell carcinoma with neoplastic tumor thrombus focusing on postoperative survival.

\section{Materials AND MEthods}

In the period between 2002 and 2012, we observed 67 cases of kidney tumor with neoplastic thrombosi. We stratified patients according clinical presentation, pathological staging and therapeutic approach applied and compared with tumor thrombus level using the chi-square test.

Kaplan-Meyer method was used to estimate cancer-specific survival. 
We registered the main clinical perioperative variables to evaluate possible different outcomes related to thrombus extension, according to Neves and Zincke classification (7). In collaboration with the Oncology Division of our institution, we extracted survival data of patients that attended our hospital for follow up, unfortunately only about $50 \%$ of the total surgical series.

\section{RESULTS}

At the time of diagnosis, mean patients age was 71.5 years (range 3-91) with a median of 72 years, 39 patients (58.2\%) were males and 28 (41.8\%) were females.

The tumor interested the right kidney in 39 cases (58.2\%) and left in 28 (41.8\%).

The mean diameter of the neoplastic primitive mass was $9.4 \mathrm{~cm}$, diameter ranged from a minimum of $3 \mathrm{~cm}$ to complete involvement of the whole organ with masses of up to $20 \mathrm{~cm}$.

There were $40(59.7 \%)$ cases of level I thrombus, 17 (25.37\%) with level II, 2 (2.98\%) with level III and 8 (11.94\%) with supra-diaphragmatic and intra-cardiac tumor thrombus (level IV). Neoplastic thrombosis level was assessed according to Neves and Zincke criteria (7) (Figure 1, Table 1).

At the time of diagnosis, most of our patients presented with definite symptoms, like local flank pain, hematuria

Figure 1.

Percentage of neoplastic thrombosis level in our series of patients (Varese, 2012).

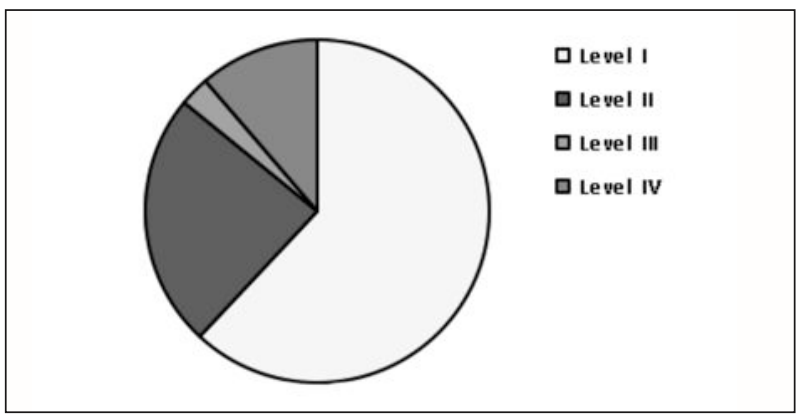

Table 1.

Surgical data and hospitalization data in our series of patients (Varese, 2012).

\begin{tabular}{|lcccc|}
\hline Thrombus level & $\mathbf{~}$ & $\mathbf{~ I}$ & III & IV \\
\hline $\begin{array}{l}\text { Operative time } \\
\text { (min.) }\end{array}$ & 158 & 175 & 215 & 289 \\
\hline Blood Supplement & 0,8 & 1,6 & 2 & 4,6 \\
(U RBC) & $(0-4)$ & $(0-6)$ & $(1-3)$ & $(3-8)$ \\
\hline Hospitalization & 14,4 & 19,3 & 20,5 & 22,6 \\
(days) & $(7-30)$ & $(8-35)$ & $(20-21)$ & $(15-52)$ \\
\hline Caval filter applied & 5 & 9 & 2 & 2 \\
& $(12,5 \%)$ & $(52,9 \%)$ & $(100 \%)$ & $(25 \%)$ \\
\hline $\begin{array}{l}\text { Peri-operative } \\
\text { complications }\end{array}$ & 13 & 7 & 1 & 3 \\
\hline
\end{tabular}

and growth of systemic inflammatory parameters (Creactive protein - CRP, erytrocite sedimentation rate ESR and leucocytes). Otherwise, 25\% was totally asymptomatic, according to most of renal carcinomas behavior. ECOG performance status was 0 in $43 \%$ of the patients, 1 in $45 \%$ and 2 in 12\% of them, and surgical indication was always integrated with an accurate anesthesiologycal evaluation.

Mean hospitalization was 16.8 days (range 7-52 days), mostly due to surgical treatment and to peri-operative surgical or medical complications.

All patients underwent clinical staging with ultra-sound (US), computed tomography (CT) and renal dynamic scintigraphy. A caval filter was placed in only 18 cases (26.87\%) to prevent pulmonary embolism during surgery, because there is not a clear indication for this procedure and the risk of thrombus detachment during caval mobilization is very low.

Patients that positioned caval filter underwent computed tomography angiography (CTA), which documented tumoral thrombosis and its extension into inferior vena cava (IVC). Cavography was performed before and after filter implantation (8). The procedure had 100\% feasibility. A right internal jugular vein puncture was performed after local anesthesia, and tumour thrombus level was determined by IVC phlebography. After the filter delivery sheath was placed in the suprarenal IVC, the filter was deployed according to the manufacturer's guidelines. There was no evidence of peri- or post-procedural complications. All suprarenal IVC filters were removed from 30 to 60 days after surgery, except in three cases, where the filter was too near to neoplastic thrombus and it was necessary to remove it intraoperatively.

Surgical aim was always the debulking of the whole tumoral mass with the associated neoplastic thrombus (9). This was not possible only in one case, where the infiltration of caval wall was extended and we had to stop the procedure. The other two cases with caval wall

Figure 2.

Surgical access stratified by level of neoplastic thrombosis (Varese, 2012).

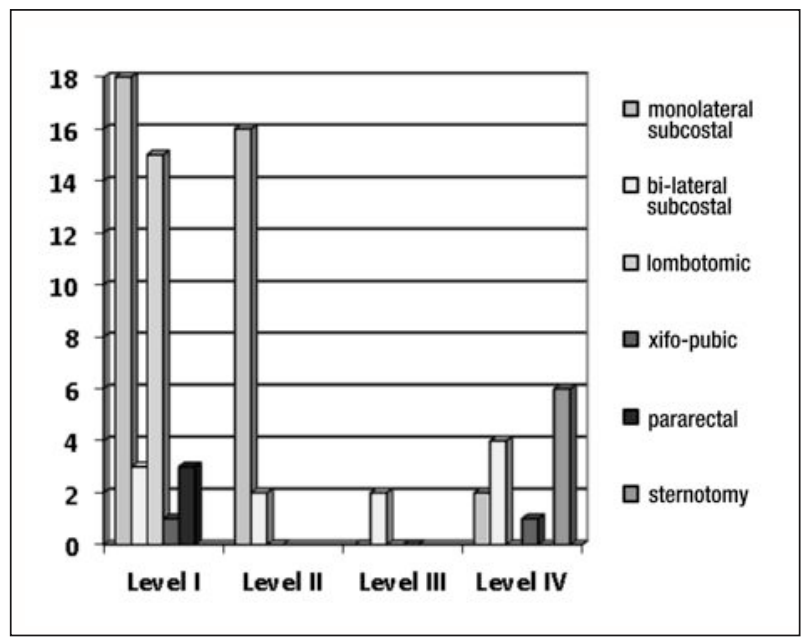


infiltration were treated with partial caval resection and apposition of a protesic biological patch.

Of the 67 patients considered in our series, 20 (30\%) had preoperatively a metastatic illness, most of them interesting lung $(30 \%, 6)$, adrenal glands $(25 \%, 5)$, liver $(20 \%, 4)$ and others brain, bone and pancreas (Figure 2$)$. Level IV thrombosis (8 cases in our series, 12\% of total),

Table 2.

Post-Surgical complications observed in our patients within the first month (Varese, 2012).

\begin{tabular}{|lc|}
\hline Postoperative Complication & Patients number/\% \\
\hline Hemorrhage/hematoma & $6 / 9$ \\
\hline Partial trombectomy & $4 / 6$ \\
\hline CVC infection & $3 / 5$ \\
\hline Anesthesiologycal & $2 / 3$ \\
\hline Lipothymia & $2 / 3$ \\
\hline Hypertensive crisis & $2 / 3$ \\
\hline PNX & $2 / 3$ \\
\hline Caval filter replacement & $2 / 3$ \\
\hline Pulmonary emboli & $2 / 3$ \\
\hline Arithmyas (FA-FV) & $2 / 3$ \\
\hline Intestinal anastomosis leakage & $2 / 3$ \\
\hline Allergic reactions & $1 / 1,5$ \\
\hline Pneumonitis & $1 / 1,5$ \\
\hline Paralytic lleus & $1 / 1,5$ \\
\hline
\end{tabular}

was always managed with cardiopulmonary bypass (CPB) and hypothermic circulatory arrest to achieve control on atrial region, in collaboration with a heart surgeon (10). We did not have neither perioperative deaths nor reinterventions, and the list of early complications is presented in the following chart (Table 2).

At pathological evaluation, 60 cases were renal clear cell carcinomas (90\% of total), 4 were urothelial papillary neoplasms of renal pelvis (6.67\% of total), one was a nefroblastoma ( $1,5 \%$ of total), one a squamous cell carcinoma of the renal pelvis and one an unclassifiable renal tumor.

In the 60 clear cell RCC, 27 (45\%) were T3a with thrombus limited to the first $2 \mathrm{~cm}$ of vena cava or within the renal vein, 21 (35\%) were T3b, extended into the IVC, 7 (12\%) were T3c, extended over the diaphragm, and 5 (8\%) were T4 extended beyond Gerota fascia, with a thrombus that involved renal vein in three cases, vena cava in one and supra-diaphragmatic region in another one.

We did not perform extended lymphadenectomy, according to European Association of Urology (EAU) guidelines, removing only big size or palpable nodes in six cases (9\% of total). Fuhrman grade was G2 in 37 cases (61.6\%) and G3 in 23 (38.4\%) (Table 3).

The 35 patients in our follow-up are divided in 24 with level I tumor thrombus, 6 with level II, 2 with level III and 3 with level IV neoplastic thrombosis. We present our survival data. Among those 35 patients, 23 (65.7\%) developed metastasis or local neoplastic recurrence, in 21 cases very soon, during the first year after surgery. The metastatic site was mainly pulmonary or hepatic (Tables 4, 5).

Table 3.

Post-Surgical complications observed in our patients within the first month (Varese, 2012).

\begin{tabular}{|cccccccc|}
\hline Primitive tumor extension & Number of patients & NOM0 & N+M0 & NOM+ & N+M+ & $\mathbf{p}$ & Patients with follow-up data \\
\hline T3a & 27 & 21 & 2 & 3 & 1 & & 15 \\
T3b & 21 & 15 & - & 6 & - & & 15 \\
T3c & 7 & 3 & 1 & 3 & - & $<0,01$ & 3 \\
T4 & 5 & 1 & - & 2 & 2 & 2 \\
\hline Tot. & 60 & 40 & 3 & 14 & 3 & & 35 \\
\hline
\end{tabular}

Table 4.

Patients stratification by tumoral thrombosis level and survival data (Varese, 2012).

\begin{tabular}{|cccccc|}
\hline Thrombus level & Number of patients & Mean survival (months) & Median survival (months) & Survival range (months) & Deaths \\
\hline I & 24 & 24,54 & 22 & $5-60$ & $6(25 \%)$ \\
\hline II & 6 & 25,1 & 21 & $14-44$ & $2(33,3 \%)$ \\
\hline III & 2 & 42 & 42 & $36-48$ & 0 \\
\hline IV & 3 & 23,66 & 24 & $12-35$ & $2(66,6 \%)$ \\
\hline
\end{tabular}

Table 5.

Patients stratification by tumor extension and survival data (Varese, 2012.

\begin{tabular}{|c|c|c|c|c|c|}
\hline Pathologist stadiation & Number of patients & Mean survival (months) & Median survival (months) & Survival range (months) & Deaths \\
\hline NOMO & 25 & 28,44 & 27 & $5-60$ & $4(16 \%)$ \\
\hline $\mathrm{N}+\mathrm{MO}$ & 1 & 12 & 12 & 12 & $1(100 \%)$ \\
\hline $\mathrm{NOM}+$ & 8 & 19,75 & 15 & $5-35$ & $4(50 \%)$ \\
\hline $\mathrm{N}+\mathrm{M}+$ & 1 & 6 & 6 & 6 & $1(100 \%)$ \\
\hline
\end{tabular}


As we can see, tumor thrombus level is not so relevant in predicting survival and life expectancy is more stratified if patients are divided by pathologist stadiation (11).

The four cases of urothelial neoplasms of renal pelvis were 3 with Level I tumoral thrombosis and 1 with level II; all of them had aggressive histological subtype, G3 Fuhrman's grade. They underwent uretero-nephrectomy with cystoscopy to exclude bladder invasion and associated trombectomy. All these cases had metastatic invasion, mainly in adrenals, lung and local lymph nodes. Their mean survival was 14.25 months (range 11-18) and they had adjuvant chemotherapy with paclitaxel. They unusually represent about $6 \%$ of our series, because only few cases of Transitional cell carcinoma with neoplastic tumoral thrombosis are presented in literature $(12,13)$. It is evident that these tumors have a high malignancy, with poor life expectancy for the patient.

The three cases with rare histological type (nephroblastoma, spinocellular tumor of the renal pelvis and unclassifiable neoplasm) were all aggressive tumors, with level I tumor thrombus, and their survival was less than one year. Despite poor prognosis, surgery was made for palliation, and patients achieved symptoms relief, mainly from hematuria that troubled most of them.

\section{Discussion}

For the 60 cases of clear cell RCC the most significant prognostic factors are local tumor extension and Fuhrman's grading.

On the contrary thrombus extension is more important for surgical planning than for predicting survival.

These inferences are clearly valuable in the KaplanMeyer comparison of survival curves of the group without and with metastatic disease at pathological evaluation (Figure 3).

According to most of literature, radical surgery is the best option to adopt. Cytoreductive aim is also useful for patients with metastatic disease, to achieve better answer to adjuvant immunotherapy on residual neoplastic foci after debulking.

Surgery is even important to give palliation to neoplastic symptoms, like local flank pain or hematuria, that occur with progressive neoplastic enlargement.

Figure 3.

Kaplan-Meyer survival curves; group 1 (continue line) are NOMO patients, group 2 (dotted line) are patients with metastatic disease

(Varese, 2012).

Time is expressed in months
Survival at 36 months is clearly better for patients without metastatic disease (about 70\%), but surgery offers a better life expectance also for advanced tumors (20\% survival at 36 months).

\section{Conclusions}

This work confirmed that RCC with neoplastic thrombosis is still a relevant health problem, with up to $10 \%$ of occurrence out of all patients with renal tumor.

Surgical treatment is clearly the first option for this pathology, and neoplastic thrombosis does not decline patients survival as an independent prognostic factor, but has to be evaluated together with tumor extension and performance status of the patient.

The only difference is related to the surgical technique, more complex if tumoral thrombosis is spread to the whole IVC or even to right atrium, with the need of CPB. Caval filter implantation is feasible and can be used to make safer the surgical procedure if thrombosis rises up into sub-diaphragmatic IVC with no complications in our series during its positioning or removal.

In spite of all, surgery is effective both in oncological or palliative aim, and mainly safe with the absence of early post-operative deaths or re-operations. Our experience in this field is in keeping with international guidelines, both in term of surgical approach and oncological follow-up.

A different conclusion has to be made for the seven cases of uncommon renal tumor histotypes (four urothelial tumors of renal pelvis, one nefroblastoma, one spinocellular tumor of the renal pelvis and one unclassifiable renal carcinoma, accounting for $10.4 \%$ of our series), where the presence of neoplastic thrombosis was always linked to poor survival (about one year).

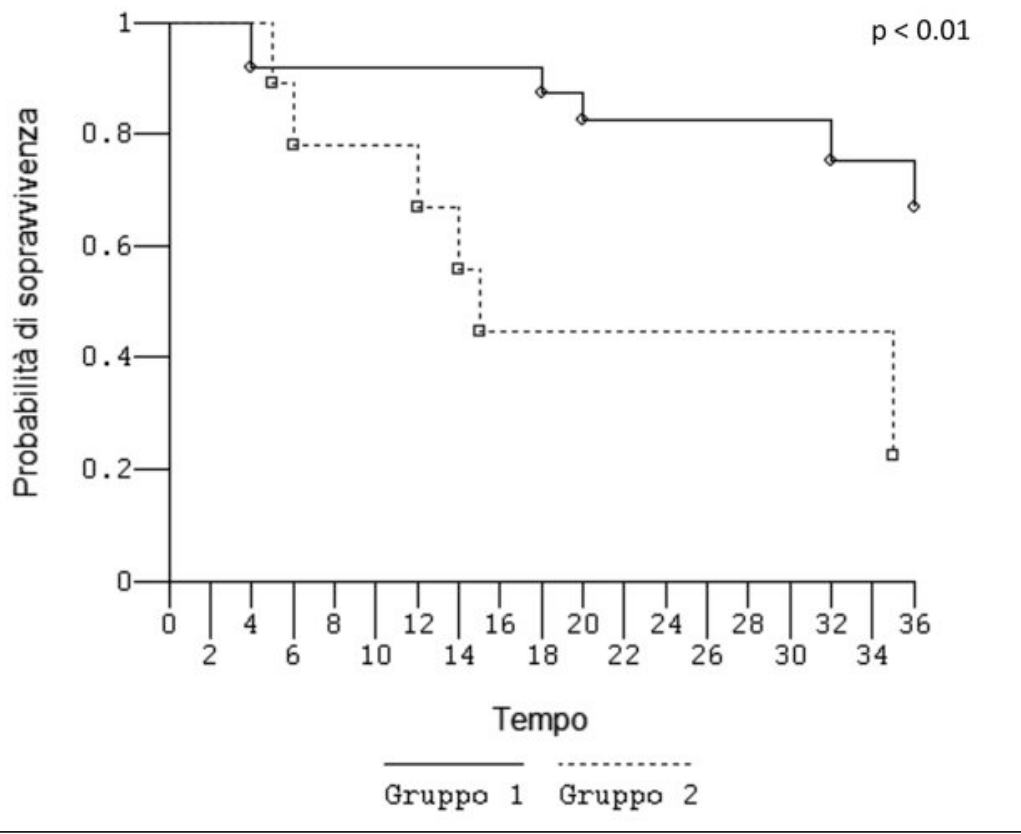




\section{References}

1. Boorjian SA, Sengupta S, Blute ML Renal cell carcinoma: vena caval involvement BJU Int. 2007; 99:1239-1244.

2. Ljungberg B, Stenling R, Osterdahl B, et al. Vein invasion in renal cell carcinoma: impact on metastatic behavior and survival. J Urol. 1995; 154:1681-1684.

3. Zisman A, Wieder JA, Pantuck AJ, et al. Renal cell carcinoma with tumor thrombus extension: biology role of nephrectomy and response to immunotherapy. J Urol. 2003; 169:909-916.

4. Castelli P, Caronno R, Piffaretti G, et al. Surgical treatment of malignant involvement of the inferior vena cava. Int Semin Surg Oncol. 2006; 16:3-19.

5. Wotkowicz C, Libertino JA, Sorcini A, Mourtzinos A. Management of renal cell carcinoma with vena cava and atrial thrombus: minimal access vs median sternotomy with circulatory arrest. BJU Int. 2006; 98:289-97.

6. Blute ML, Leibovich BC, Lohse CM, et al. The Mayo Clinic experience with surgical management, complications and outcome for patients with renal cell carcinoma and venous tumor thrombus. BJU Int. 2004; 94:33-41.
7. Neves RJ, Zincke H. Surgical treatment of renal cancer with vena cava extension. Br J Urol. 1987; 59:390

8. Carrafiello G, Mangini M, Fontana F, et al. Suprarenal inferior vena cava filter implantation. Radiol Med. 2012; 117:1190-8.

9. Flanigan RC, Mickisch $G$, Sylvester $R$, et al. Citoreductive nephrectomy in patients with metastatic renal cancer: a combined analysis. J Urol. 2004; 171:1071-6.

10. Belgrano E, Trombetta C, Siracusano S, et al. Surgical treatment of renal cell carcinoma (RCC) with vena cava tumor thrombus. Eur Urol Suppl. 2006; 5:610-618.

11. Skinner DG, Pritchett TR, Lieskovsky G, et al. Vena caval involvement by renal cell carcinoma. Surgical resection provides meaningful long-term survival. Ann Surg. 1989; 210:387-92.

12. Prando A, Prando P, Prando D. Urothelial cancer of the renal pelvicaliceal system: unusual imaging manifestations. Radiographics. 2010; 30:1553-66.

13. Miyazato M, Yonou H, Sugaya K, Koyama Y, et al. Transitional cell carcinoma of the renal pelvis forming tumor thrombus in the vena cava. Int J Urol. 2001; 8:575-7.

\section{Correspondence}

Giacomo Maria Pirola, MD (Corresponding Author) gmo.pirola@gmail.com

Giovanni Saredi, MD giovannisaredi@yahoo.it

Giuseppe Damiano, MD mediciurologia@ospedalivarese.net

Alberto Mario Marconi, MD

Albertomario.marconi@ospedale.varese.it

Division of Urology, Ospedale di Circolo e Fondazione Macchi, Viale Borri 57, 21100 - Varese, Italy 